Departamento de História - Faculdade de Ciências Humanas e Sociais - Unesp-Franca Av Eufrásia Monteiro Petráglia, 900 14409-160 - Franca - SP saenzl@terra.com.br

\section{SOBERANIA E FISCALIDADE NO BRASIL INDEPENDENTE: CONCEPÇÕES DA IMPRENSA PAULISTA*}

\author{
Marisa Saenz Leme ${ }^{* *}$ \\ Universidade Estadual Paulista Júlio de \\ Mesquita Filho
}

Franca - São Paulo - Brasil

\title{
Resumo
}

Neste artigo busca-se compreender o modo pelo qual os liberais moderados paulistas chegaram a formular o que teoricamente veio a se conceituar como monopólio fiscal, impreterível para a constituição do Estado moderno, também em sua dimensão liberal. Para tanto são utilizadas as matérias publicadas na imprensa paulista do $1^{\circ}$ Reinado, constituída pelos periódicos O Farol Paulistano (1827 a 1831) e O Observador Constitucional (1829 a 1831).

\section{Palavras-chave}

Liberalismo - cidadania - fiscalidade.

* O presente artigo resulta do desenvolvimento de trabalho apresentado no XVII Congresso de Ahila, Berlim, 2014, com auxílio da Capes.

** Doutora pelo Programa de Pós-Graduação em História Econômica no Departamento de História da Faculdade de Filosofia, Letras e Ciências Humanas da Universidade de São Paulo. Professora no Departamento de História da Faculdade de Ciências Humanas e Sociais da Universidade Estadual Paulista. 
Contact

Departamento de História - Faculdade de Ciências Humanas e Sociais - Unesp-Franca Av Eufrásia Monteiro Petráglia, 900 14409-160 - Franca - SP

\section{SOVEREIGNTY}

AND TAXATION

IN INDEPENDENT

BRAZIL:

CONCEPTS IN THE

NEWSPAPERS OF

THE SÃO PAULO

PROVINCE

\section{Marisa Saenz Leme}

Universidade Estadual Paulista Júlio de Mesquita Filho

Franca - São Paulo - Brazil

\section{Abstract}

This article discuss by which set of ideas the so called "moderate liberals" in the province of São Paulo came to give form to what achieved to be theoretically known as a monopoly on taxation, imperative for the creation of the modern state, even in it's liberal dimension. Empirical data for this analysis are provided by the subjects found in the newspapers published in São Paulo during Brazilian's first kingdom: O Farol Paulistano (1827 to 1831) and O Observador Constitucional (1829 to 1831).

\section{Keywords}

Liberalism - citizenship - taxation. 


\section{Imprensa paulista e correntes políticas}

Em que pese sua notória participação juntamente com Minas Gerais e Rio de Janeiro no modo por que se processou a separação de Portugal e como se deram os primeiros passos para a formação do estado independente no Brasil, a província de São Paulo - contrariamente a outras localidades do território que politicamente veio a compor a monarquia constitucional brasileira - chegou a conhecer o seu primeiro jornal impresso apenas em 1827.

Observe-se que, nas atividades de imprensa eclodidas no Brasil a partir de 1821, com a liberação da censura em consequência da Revolução Liberal do Porto em agosto de 1820, além do Rio de Janeiro - onde naturalmente surgiram vários jornais e pasquins com diversos posicionamentos e projetos a respeito do agitado momento político que então se vivia - destacaram-se as Províncias do atual Norte, Maranhão e Pará, e, sobretudo, do atual Nordeste, Pernambuco e Bahia. Nelas apareceram, ainda que em quantidade inferior à da Corte, diversos jornais contemplando diferentes matizes de posicionamento em relação quer à lealdade a Lisboa, quer às possibilidades de autonomia, e, no limite, de separação. Já nas Províncias do Sudeste e também do Sul, a imprensa tardou mais a surgir, acontecendo apenas no início da formação do estado independente.

Essa distribuição geopolítica pode ser em parte explicada pelas diferenças nos direcionamentos em relação ao centro político que então se gestava no Rio de Janeiro: as Províncias em que houve nesse momento maior atividade de imprensa foram também aquelas onde adquiriram grande visibilidade as tendências as mais refratárias quer à separação, quer à formação de um todo político unitário abrangendo o ex-território colonial. Diferentemente, no Sudeste, São Paulo e Minas Gerais se articulavam ao Rio de Janeiro e a ausência de imprensa nessas Províncias durante o processo iniciado com a Revolução do Porto permite levantar a hipótese de estarem as suas elites suficientemente representadas nos periódicos surgidos na capital então a se constituir. Tendência essa que, indica-se, era acompanhada no Rio Grande do Sul.

Mas essa situação se modificou com a formação do estado independente. Passaram então essas mesmas elites a se manifestar com imprensa própria, o que refletia quer os matizes de posicionamentos já então referidos à construção do Estado nacional, quer as divergências internas às próprias Províncias articuladoras da independência. Em Minas Gerais, o seu primeiro periódico, O Compilador Mineiro, surgiu em Ouro Preto (então capital da província) em outubro de 1823, sintomaticamente um mês antes da dissolução 
da Constituinte. Observe-se também tratar-se de um título apontando uma regionalização de perspectivas. ${ }^{1}$

Também em São Paulo deu-se a tentativa da fundação de um jornal e o estabelecimento de uma tipografia oficial, o que não se realizou devido a desentendimentos entre as autoridades provinciais e o governo central. As perspectivas políticas do projeto acabaram por se explicitar em um jornal manuscrito, $O$ Paulista, fundado em setembro de 1823, que teve alguns meses de duração. Para tanto reuniram-se amanuenses e copistas, pagos por uma "sociedade patriótica", evidenciando-se um princípio de organização social para o desenvolvimento da imprensa na Província. O periódico era editado por Antônio Mariano de Azevedo Marques, que elaborara "O plano para o estabelecimento de uma tipografia em São Paulo". ${ }^{2}$

No plano de governo, o primeiro presidente indicado da província de São Paulo - Lucas Monteiro, futuro visconde de Congonhas - não poupou esforços no sentido de conseguir montar uma tipografia oficial na Província, no que também não obteve êxito. Na oportunidade, lamentaram-se os membros do Conselho da Presidência - organismo eleito, de acordo com lei emanada da Assembleia Constituinte, em outubro de 1823 - alegando exiguidade de recursos públicos destinados à Província. Na recusa do Rio de Janeiro, afirmava-se que contribuir para a criação de imprensa em São Paulo significaria retirar da capital a possibilidade de ela própria contar com recursos para tanto. ${ }^{3}$

Apesar dos esforços conjugados entre elites locais, presidente indicado pelo governo central e Conselho da Presidência, foi apenas em fevereiro de $1827^{4}$ que surgiu o primeiro periódico impresso em São Paulo, O Farol Paulista-

\footnotetext{
1 As informações sobre a imprensa em Minas Gerais e São Paulo foram articuladas com base nas seguintes obras: CONTIER, Arnaldo. Imprensa e ideologia em São Paulo (1822-1842). São Paulo: Vozes, 1979; FREITAS, Afonso A. de. A imprensa periódica de São Paulo desde os seus primórdios em 1823 até 1914. Separata da Revista do Instituto Historico e Geographico de São Paulo, vol. XVI. São Paulo: Typ. do "Diario Official", 1915; OLIVEIRA, Carlos Eduardo França. Poder local e palavra impressa: a dinâmica política em torno dos conselhos provinciais e da imprensa periódica em São Paulo. Dissertação de mestrado, FFLCH-USP, 2010; SILVA, Wlamir. Liberais e povo: a construção da hegemonia liberal-moderada na província de Minas Gerais. São Paulo: Hucitec, 2008; SODRÉ, Nelson Werneck. História da imprensa no Brasil. Rio de Janeiro: Civilização Brasileira, 1966.

2 CONTIER, Arnaldo. Imprensa e ideologia em São Paulo (1822-1842). São Paulo: Vozes, 1979, p. 35 e ss.

3 FREITAS, Affonso A. de. A imprensa periódica de São Paulo desde os seus primórdios em 1823 até 1914. Separata da Revista do Instituto Historico e Geographico de São Paulo, vol. XVI. São Paulo: Typ. do "Diario Official", 1915, p. 23 e ss.

${ }^{4}$ Nesse mesmo ano deu-se a fundação do primeiro jornal impresso do Rio Grande do Sul, Diário de Porto Alegre, no mês de junho. Observem-se ainda outras diferenças entre as principais Províncias
} 
rev. hist. (São Paulo), n. 173, p. 277-302, jul.-dez., 2015 http://dx.doi.org/10.11606/issn.2316-9141.rh.2015.107670
Marisa Saenz Leme

Soberania e fiscalidade no Brasil independente: concepções da imprensa paulista

no, simultaneamente à fundação da primeira tipografia paulista, de iniciativa particular, denominada Typographia de Roa e Cia. ${ }^{5}$ Pertencia a José da Costa Carvalho, futuro marquês de Monte Alegre, também diretor e redator do periódico. Figura que alcançou grande projeção nacional, ocupando significativos espaços parlamentares durante o $1^{\circ}$ Império, era ele originário da Bahia, tendo amealhado fortuna com base em São Paulo. Naquele momento, situava-se claramente no campo da oposição liberal-moderada ao imperador. ${ }^{6}$

Em que pese o caráter difuso dos campos políticos que se articulavam na época, os "moderados" formavam uma corrente que, naquele momento, compunha o campo unitário - no sentido do apoio à constituição de uma centralidade soberana no Rio de Janeiro - ao mesmo tempo em que estimulava o desenvolvimento do Legislativo, na sua dimensão da Câmara baixa, em rela-

articuladoras da Independência: em Minas Gerais, durante o $1^{\circ}$ Reinado, fundaram-se diversos periódicos, de duração variada, em Ouro Preto; por sua vez, em 1827, a imprensa surgia em São João d'El Rei e, em 1828, em Diamantina. Em São Paulo, nesse período, existiram apenas os jornais $O$ Farol Paulistano e O Observador Constitucional, este fundado em outubro de 1829. Apenas com a Abdicação é que surgiram novos jornais na capital; por sua vez, o primeiro periódico do interior paulista veio a aparecer somente em 1842, em Sorocaba, cidade profundamente envolvida com a Revolução Liberal de São Paulo e Minas Gerais, desencadeada nesse mesmo ano.

5 OLIVEIRA, Carlos Eduardo França de. Poder local e palavra impressa: a dinâmica política em torno dos conselhos provinciais e da imprensa periódica em São Paulo. Dissertação de mestrado, FFLCH-USP, 2010, p. 60.

6 José da Costa Carvalho teve atuação política bastante controvertida, o que não destoava de boa parte dos denominados "fundadores do Império". Formado em Coimbra, sua atuação em São Paulo, iniciada pela magistratura, percorreu um zigue-zague de posicionamentos nos matizes políticos da época. No período da Independência, na qualidade de ouvidor interino na capital de São Paulo, participou da bernarda de Francisco Inácio, movimento de análise historiográfica controvertida, mas com teor conservador para o contexto político da época. Conforme a historiografia, Costa Carvalho teria sido seu mentor intelectual. No início da Maioridade, o então barão de Monte Alegre governava São Paulo em nome do Partido Conservador, tendo atuado significativamente na repressão aos revoltosos de 1842. No campo parlamentar, durante o $1^{\circ}$ Império, foi deputado geral pela Bahia nas legislaturas de 1826 a 1830, vice-presidente da Câmara em 1827, e seu presidente em 1828 e 1830. Participou da Regência Trina Permanente (17-06-1831 a 18-07-1833), tendo, durante as regências e o Segundo Reinado, ocupado altos cargos executivos, participado do Senado e do Conselho de Estado. Durante curto período, entre dezembro de 1835 e junho de 1836, foi diretor da Faculdade de Direito de São Paulo. Exerceu funções culturais, tendo sido sócio do IHGB. Em 1854, recebeu o título de marquês. Informações articuladas a partir dos seguintes trabalhos: AMARAL, Antônio Barreto do. Dicionário de história de São Paulo. São Paulo: Governo do Estado, 1980; CONTIER, Arnaldo. Imprensa e ideologia em São Paulo (1822-1842), op. cit., 1979; DELATORRE, Aparecida Vanessa. São Paulo à época da Independência: Contribuição para o estudo do chamado movimento "bernardista", 1821/1823. Dissertação de mestrado, FFLCH-USP, dez/2003; José da Costa Carvalho (marquês de Monte Alegre). In: VAINFAS, Ronaldo (dir.). Dicionário do Brasil imperial (1822-1889). Rio de Janeiro: Objetiva, 2002; VIDAL, Geraldo. O marquês de Monte Alegre: alvorecer de um estadista. São Paulo: Ibrasa, 1999. 
rev. hist. (São Paulo), n. 173, p. 277-302, jul.-dez., 2015 http://dx.doi.org/10.11606/issn.2316-9141.rh.2015.107670
Marisa Saenz Leme

Soberania e fiscalidade no Brasil independente: concepções da imprensa paulista

ção ao Executivo. Entre outros fatores, a organização jurídico-administrativa do país em formação constituía-se num dos seus principais alvos políticos.7

Costa Carvalho era muito articulado a Evaristo da Veiga ${ }^{8}$ que, como se sabe, teve papel fundamental na expressão pública dessa corrente política, por intermédio do seu jornal, Aurora Fluminense, fundado alguns meses depois do surgimento d'O Farol Paulistano, periódicos cujos títulos muito se assemelhavam nos seus significados, dado o caráter anunciador/iluminador de "aurora" e "farol", e a identificação regional dada por "fluminense" e "paulistano". Ainda, artigos desse jornal eram reproduzidos nos jornais mineiros, sobretudo no Universal e no Astro de Minas, de fundamental importância como veículos de expressão dos liberais moderados nessa Província.?

Ao lado do seu proprietário, o principal redator d'O Farol Paulistano foi Antônio Mariano de Azevedo Marques, ${ }^{10}$ o que representava uma continuidade de procedimentos no seio das elites paulistas em relação ao estabelecimento da imprensa na Província. Era ele significativamente cognominado "o Mestrinho", dada a relevância das suas atividades didáticas dentre os vários papéis públicos que desempenhou, todos na Província: professor de primeiras letras de latim e retórica; na área jurídica, embora não tivesse formação específica, advogava por experiência e foi juiz de paz; na dimensão legis-

\footnotetext{
7 Para uma discussão bastante matizada da evolução dos posicionamentos políticos que se apresentaram no Rio de Janeiro durante o $1^{\circ}$ Império e regências ver: MOREL, Marco. As transformações dos espaços públicos: imprensa, atores políticos e sociabilidades na cidade imperial (18201840). São Paulo: Hucitec, 2005; BASILE, Marcelo. Projetos de Brasil e construção nacional na imprensa fluminense (1831-1835). In: NEVES, Lúcia Maria Bastos P. Neves; MOREL, Marco; FERREIRA, Tania Maria Bessone da C. História e imprensa: representações culturais e práticas de poder. Rio de Janeiro: Faperj/DP \& A Ed., 2006. Para Minas Gerais, ver: SILVA, Wlamir. Liberais e povo: a construção da hegemonia liberal-moderada na província de Minas Gerais. São Paulo: Hucitec, 2008.

8 Evaristo Ferreira da Veiga teve origem socialmente modesta, mas intelectualmente rica, com pai professor régio de primeiras letras e, depois, dono de uma das poucas livrarias existentes no Rio de Janeiro do $1^{\circ}$ Reinado. Jornalista e poeta, continuou a atividade do pai como livreiro. Em 1830, elegeu-se deputado por Minas Gerais, sendo sucessivamente reeleito. Pertenceu à Loja Maçônica Esperança de Nictheroy, ao Instituto Histórico de França e à Arcádia de Roma (SOUSA, Octavio Tarquínio de. História dos fundadores do Império do Brasil, vol. VII. Evaristo da Veiga. Rio de Janeiro: José Olympio, 1957; Evaristo da Veiga. In: VAINFAS, Ronaldo (dir.). Dicionário do Brasil imperial, op. cit, 2002, p. 247-8.

9 SILVA, Wlamir. Liberais e povo: a construção da hegemonia liberal-moderada na província de Minas Gerais. São Paulo: Hucitec, 2008, p. 132.

${ }^{10}$ Ao que se indica, outros redatores participavam d'O Farol Paulistano, mas de modo secundário (OLIVEIRA, Carlos Eduardo França de. Poder local e palavra impressa: a dinâmica política em torno dos conselhos provinciais e da imprensa periódica em São Paulo, op. cit., 2010, p. 64).
} 
rev. hist. (São Paulo), n. 173, p. 277-302, jul.-dez., 2015 http://dx.doi.org/10.11606/issn.2316-9141.rh.2015.107670
Marisa Saenz Leme

Soberania e fiscalidade no Brasil independente: concepcões da imprensa paulista

lativa, vereador e membro do Conselho Geral da Província; no Executivo, secretário-geral da Presidência e vice-presidente da Província.

Por sua vez, o jornal contava com colaboradores, a maioria deles, na época, sediados basicamente em São Paulo, como os padres Vicente Pires da Mota e Manoel Joaquim do Amaral Gurgel, além do futuro lente da Faculdade de São Francisco, então estudante, João da Silva Carrão. ${ }^{11}$ Como elemento de projeção nacional, destacava-se enquanto colaborador do jornal o "bacharel e fazendeiro" Nicolau de Campos Vergueiro. ${ }^{12}$ Constituíam um grupo relativamente jovem. Nas extremidades, Vergueiro, então com 49 anos, e Silva Carrão, com 17; os demais, inclusive o futuro marquês de Monte Alegre, tinham entre 28 e 31 anos. Com exceção de Silva Carrão, ainda menor, e de Vergueiro, eleito senador em 1828, vieram todos, redatores e colaboradores do jornal, a pertencer ao Conselho Geral da Província, organismo de caráter eletivo previsto na Carta de 1824 e efetivamente instituído em São Paulo em 1828. ${ }^{13}$ Alguns deles participaram também do Conselho da Presidência e o

\footnotetext{
${ }^{11}$ Os padres Vicente Pires da Mota e Amaral Gurgel tiveram origem socialmente humilde. Por conta da ação de benfeitores, conseguiram formar-se no Curso Jurídico de São Paulo, do qual fizeram parte posteriormente como lentes e, mais para o fim da vida, diretores. Liberais, ambos se elegeram deputados à Assembleia Provincial, criada com o Ato Adicional de 1834. Vicente Pires foi por duas vezes presidente de Província, tendo sido ainda por várias vezes seu vice-presidente. Amaral Gurgel foi por várias vezes vice-presidente da Província. Durante as regências, chegou a tomar assento na Assembleia Geral como suplente. Já Silva Carrão, embora bastante vinculado a São Paulo, tendo sido deputado provincial em vários biênios e o $32^{\circ}$ presidente da Província, projetou-se também nacionalmente. A partir de 1842, elegeu-se deputado à Assembleia Geral por vários triênios; foi presidente da província do Pará em 1857, e ministro da Fazenda do gabinete presidido pelo marquês de Olinda; foi eleito senador em 1878. Importa salientar que foi redator do Novo Farol Paulistano, fundado em 1831 (CARVALHO, José da Costa (marquês de Monte Alegre). In: AMARAL, Antônio Barreto do. Dicionário de história de São Paulo, op. cit., 1980, p. 116-7).

${ }_{12}$ Português de nascimento, formado em Coimbra, amealhou fortuna em São Paulo por intermédio de atividades agrárias e, grandemente, devido ao comércio escravista. Foi eleito deputado às Cortes de Lisboa e, sucessivamente, deputado da Constituinte e da Assembleia Geral por São Paulo; em 1828, elegeu-se senador por Minas Gerais. Destacou-se posteriormente devido às suas experiências pioneiras com a imigração europeia no Brasil. (Nicolau de Campos Vergueiro. In: VAINFAS, Ronaldo (dir.). Dicionário do Brasil imperial, op. cit., 2002, p. 550 e ss). No momento da fundação d'O Farol, era membro do Conselho da Presidência, então no início da sua segunda "reunião".

${ }^{13}$ Os conselhos de presidência, instituídos por lei de outubro de 1823 - emanada da Assembleia Geral Constituinte e Legislativa das Províncias do Brasil -, eram eletivos e de consulta obrigatória para a deliberação de grande parte dos assuntos provinciais; por sua vez, os conselhos gerais de Província, estabelecidos pela Constituição de 1824, continham importantes possibilidades políticas, que podem ser consideradas como "proto-legislativas". Para os conselhos ver: LEME, Marisa Saenz. Dinâmicas centrípetas e centrífugas na formação do Estado monárquico no Brasil. Revista Brasileira de História, v. 28, 2008, p. 197-215; LEME, Marisa Saenz. São Paulo no $1^{\circ}$ Império: poderes locais e governo central. In: OLIVEIRA, Cecília Helena de Salles; PRADO, Maria Ligia
} 
rev. hist. (São Paulo), n. 173, p. 277-302, jul.-dez., 2015 http://dx.doi.org/10.11606/issn.2316-9141.rh.2015.107670
Marisa Saenz Leme

Soberania e fiscalidade no Brasil independente: concepcões da imprensa paulista

periódico contou, ainda, com a contribuição do jornalista e político maranhense Manuel Odorico Mendes.

O segundo jornal impresso de São Paulo, O Observador Constitucional, foi dirigido por Giovanni Battista Líbero Badaró, trazido do Rio de Janeiro para São Paulo por Costa Carvalho. Teriam eles se conhecido na livraria de onde saiu posteriormente o jornal Aurora Fluminense, cuja fundação teria sido assistida ${ }^{14}$ pelo "jovem médico italiano". Propriedade de Evaristo da Veiga, era a livraria uma das "mais prósperas" da cidade, tendo-se transformado "em ponto de reunião de políticos e beletristas",15 um típico espaço daqueles em que se encontravam os formadores de opinião na sua dimensão burguesa. Afonso Schmidt descreve seu ambiente de debate político, em que se congregavam "alguns inimigos do sr. dom Pedro I".16

Apesar de impresso na própria tipografia d'O Farol, escasseiam as informações bibliográficas sobre $O$ Observador Constitucional, no sentido de um melhor conhecimento sobre o seu corpo redatorial: "é sabido que, além de dirigi-lo, Líbero Badaró ${ }^{17}$ também era seu principal editor, mas é improvável que tenha sido o único, uma vez que os artigos principais eram assinados por

Coelho; JANOTTI, Maria de Lourdes Mônaco (org.). A história na política, a política na história. São Paulo: Alameda/Programa de Pós-Graduação em História Social USP, 2006, p. 59-80; OLIVEIRA, Carlos Eduardo França de. Poder local e palavra impressa: a dinâmica política em torno dos conselhos provinciais e da imprensa periódica em São Paulo, op. cit., 2010; OLIVEIRA, Carlos Eduardo França de. Construtores do Império, defensores da província: São Paulo e Minas Gerais na formação do Estado nacional e dos poderes locais, 1823-1834. Tese de doutorado, São Paulo, FFLCH-USP, 2014. SLEMIAN, Andrea. Sob o império das leis: constituição e unidade nacional na formação do Brasil (1822-1834). São Paulo: Hucitec, 2009.

${ }^{14}$ SODRÉ, Nelson Werneck. História da imprensa no Brasil. Rio de Janeiro: Civilização Brasileira, 1966, p. 129.

${ }^{15}$ VAINFAS, Ronaldo (dir.). Dicionário do Brasil imperial, op. cit., 2002, p. 247.

${ }^{16}$ SCHMIDT, Afonso. São Paulo de meus amores. São Paulo: Paz e Terra, 2003, p. 97 e ss. Para as concepções sobre a constituição da opinião pública burguesa ver: HABERMAS, Jürgen. Mudança estrutural da esfera pública. Rio de Janeiro: Edições Tempo Brasileiro, 1984; SENNET, Richard. O declínio do homem público: as tiranias da intimidade. São Paulo: Cia. das Letras, 1989.

${ }^{17}$ Com origem social elevada, Líbero Badaró possuía boa formação em línguas e filosofia. Médico e botânico, saiu da Itália por motivos políticos e veio para o Brasil com o objetivo de estudar suas flora e fauna, chegando ao Rio de Janeiro em 1826. Veio para São Paulo em 1828, hospedando-se por algum tempo na casa de Costa Carvalho. Nesta cidade, lecionava matemática e geometria, simultaneamente ao seu trabalho de editor. De acordo com os dicionários, teria colaborado com artigos para $O$ Farol. O seu assassinato, em 30 de novembro de 1830, foi grandemente imputado às suas posturas de oposição política liberal, embora se considerem também motivos pessoais para o crime. BADARÓ, João Batista Líbero. In: AMARAL, Antônio Barreto do. Dicionário de história de São Paulo, op. cit., 1980, p. 61; Líbero Badaró. In: VAINFAS, Ronaldo (dir.). Dicionário do Brasil imperial, op. cit., 2002, p. 479. 
rev. hist. (São Paulo), n. 173, p. 277-302, jul.-dez., 2015 http://dx.doi.org/10.11606/issn.2316-9141.rh.2015.107670
Marisa Saenz Leme

Soberania e fiscalidade no Brasil independente: concepcões da imprensa paulista

'os redatores'"'18 Tampouco se pode definir um corpo de colaboradores fixos do jornal, cujos artigos eram na sua maior parte anônimos. Mas, ao menos de modo esporádico, nele se publicaram textos dos colaboradores d'O Farol.

Contando com a importante contribuição de elementos que se constituíram, na província, numa intelectualidade defensora da monarquia constitucional, interligando elementos de expressão política provincial com aqueles de expressão nacional, ambos os jornais expunham concepções consideradas, já na época, ${ }^{19}$ "liberal-moderadas", numa província, volte-se a lembrar, que teve especial participação no modo como se definiram os contornos do Estado no país.

Fundado já no período de liberalização do governo de d. Pedro I, O Farol Paulistano, de acordo com Antônio de Freitas, teria sido "um dos maiores paladinos da reação liberal à política de desmandos e de absolutismo de Pedro I". ${ }^{20} \mathrm{~A}$ sua existência percorreu o progressivo desgaste do imperador. Programaticamente, opôs-se desde o início ao que formulava como o "absolutismo", o "despotismo" de d. Pedro I e criticava as atitudes "arbitrárias" dos seus ministros.

Como não poderia deixar de ser em anos tão movimentados e cruciais para a história política de um país em formação, o tom político dos referidos jornais variou nos breves anos de 1827 a 1831. Fundado num momento em que a crise em relação a d. Pedro I ainda não se firmara, O Farol Paulistano iniciou-se com posturas críticas, mas ainda relativamente moderadas, em relação ao governo central, ao mesmo tempo em que mostrava muita concordância para com o governo provincial. Observe-se que o jornal dedicava boa parte das suas matérias ao plano da política interna à Província. ${ }^{21}$

\footnotetext{
${ }^{18}$ OLIVEIRA, Carlos Eduardo França de. Poder local e palavra impressa: a dinâmica política em torno dos conselhos provinciais e da imprensa periódica em São Paulo. op. cit., 2010, p. 65.

${ }^{19}$ Idem, p. 29.

${ }^{20}$ FREITAS, Affonso A. de. A imprensa periódica de São Paulo desde os seus primórdios em 1823 até 1914, op. cit., 1915, p. 31. O jornal parou de funcionar em julho de 1831, provavelmente devido à ida de Costa Carvalho para o Rio de Janeiro, por ter sido escolhido para compor a Regência Trina Permanente. Mas logo a seguir, em agosto, fundou-se $O$ Novo Farol Paulistano, com outros redatores, mas de orientação política semelhante à do seu antecessor.

${ }^{21}$ Como se observa na historiografia dedicada à temática, a construção do Estado no Brasil não decorreu de apenas um eixo de disputas das Províncias em relação ao centro político em constituição no Rio de Janeiro, pró ou contra a centralização unitária. Deve-se atentar, simultaneamente a esse eixo tradicionalmente mais explorado, para a luta política interna às Províncias, com várias facções e projetos em disputa. Para São Paulo, é significativo ter uma das principais metas do periódico $O$ Paulista consistido na "conciliação das ideias políticas antagônicas dos grupos sociais dominantes..." na própria Província (CONTIER, Arnaldo. Imprensa e
} 
Já O Observador Constitucional - fundado num momento de extremo desgaste do governo de d. Pedro I, em outubro de 1829 - embora esposando basicamente as mesmas concepções percebidas em $O$ Farol Paulistano, no plano geral e provincial - apresentava-se com mais agressividade em relação ao Executivo nacional. Nele criticava-se o despotismo, a arbitrariedade, atacavam-se os ministros, ao mesmo tempo em que se expunham teorias de governo, discutindo-se as atribuições dos três poderes e as do Poder Moderador, sem que este fosse enquanto tal atacado.22

Importa recuperar em linhas gerais os conceitos políticos esposados nos periódicos em apreço. Observe-se que, no decorrer do $1{ }^{\circ}$ Reinado, foi sobretudo a tônica constitucional que deu o eixo das discussões então travadas, adquirindo muito pouca visibilidade os posicionamentos que se poderiam considerar de teor absolutista. Nesse quadro, a diversidade de projetos apresentados durante o processo de independência sob o manto constitucional passara a ter um alvo interno concreto: um estado independente em construção, em que cabia definir, na prática, as atribuições dos diferentes níveis de poder. Num eixo vertical, os poderes do governo central e dos provinciais e, num eixo por assim dizer horizontal, os poderes legislativos, executivos e judiciários, tanto no plano central quanto no provincial. As propostas práticas para essa construção institucional requeriam naturalmente o recurso a um arsenal teórico-conceitual.

Nesse quadro se inseria a imprensa ora analisada, desenvolvendo-se por sua vez numa época adequadamente denominada "segundo período" do $1^{0}$ Reinado, ${ }^{23} \mathrm{em}$ que se levantara a censura à imprensa e se retomara a atividade parlamentar. Isso, naturalmente, permitia uma expressão mais franca do pensamento, não havendo necessidade de recorrer a disfarces conceituais.

ideologia em São Paulo, op. cit., 1979, p. 36). Ou seja, a par ou para além das questões mais gerais em pauta no cenário nacional, em São Paulo importava grandemente a unificação interna.

${ }^{22}$ Se na historiografia existe um consenso a respeito da linha política d'O Farol Paulistano, o mesmo já não se verifica no que se refere a'O Observador Constitucional. Embora predomine a seu respeito a imagem de ter sido muito mais radical do que o primeiro, essa radicalização ocorreu a partir da Abdicação, já com outro redator, após o assassinato de Líbero Badaró, havendo, portanto, a necessidade de se cindir cronologicamente a sua avaliação. Afonso de Freitas afirmou que o jornal teria participado do mesmo "credo" de Monte Alegre. Nesse sentido, é importante o registro de Afonso Schmidt sobre Líbero Badaró: “Uns diziam-no carbonário, outros anarquista. Mas era liberal" (SCHMIDT, Afonso. São Paulo de meus amores, op. cit., 2003, p. 98).

${ }^{23}$ Expressão utilizada por J. M. Pereira da Silva como título da sua obra: PEREIRA, J. M. Segundo período do Reinado de dom Pedro I no Brazil. Rio de Janeiro: Garnier, 1871. 
O modelo ideal de estado e de governo adotado hegemonicamente pelos paulistas nesse período foi teoricamente apresentado em $O$ Farol Paulistano, logo no seu segundo número, quando, na matéria “Monarchia representativa", expuseram-se as vantagens, em todos os sentidos, dessa forma de organização do estado, destacando-se o equilíbrio entre os poderes, os limites constitucionais, a existência de ordem social e uma soberania popular "indirecta". A temática desenvolveu-se em vários números do jornal, numa série intitulada "Theoria de governar".

A questão da constitucionalidade foi abordada nos periódicos em apreço sob os mais variados ângulos, inserindo-se nos preceitos liberais clássicos adotados no início do século XIX, na constituição dos estados liberais europeus. Postulava-se a propriedade privada e a hierarquização social como constituintes da cidadania, ao mesmo tempo em que a igualdade era tomada como ponto de partida para a construção da relação entre sociedade e estado. Nesse contexto, destacavam-se, ainda de acordo com o liberalismo clássico, as concepções de ordem e legalidade.

O entendimento da legalidade como fundamento da sociedade sustentava a própria concepção constitucional, pois “o Governo regulado por leis invioláveis seria o mais conforme á prudencia e á segurança do Príncipe e do Povo". ${ }^{24}$ Ainda nos momentos finais da crise do $1^{\circ}$ Império, apresentavam-se em $O$ Observador Constitucional matérias com forte defesa da legalidade.

A defesa da ordem, ou seja, da legalidade liberal, contrapunha-se à "barbarie", que seria decorrente, quer do "absolutismo", quer da "anarchia" democrática. Neste diapasão apresentavam-se as diferenças básicas entre os próprios liberais, ou seja, entre os que foram historiograficamente considerados liberais "moderados" e os "liberais radicais". O Farol se contrapunha aos "escriptores, que representão a liberdade na imagem assustadora da anarchia...." ${ }^{25}$ Definia-se o liberal como "o homem que respeita e quer que se respeitem religiosamente as leis, e na conformação de suas acções com ellas esta o verdadeiro uso da liberdade, que não foi dada ao homem para commeter crimes...". ${ }^{26}$ Em artigo da Aurora Fluminense, reproduzido n'O Farol Paulistano sob o título "Diferença entre liberaes, e liberaes", explicitava-se:

\footnotetext{
${ }^{24}$ O Farol Paulistano, 01/12/1827. Optou-se nas citações por manter a grafia original encontrada na documentação.

${ }^{25}$ Idem, 11-07-1827.

${ }^{26}$ Idem, 14-02-1827.
} 
rev. hist. (São Paulo), n. 173, p. 277-302, jul.-dez., 2015 http://dx.doi.org/10.11606/issn.2316-9141.rh.2015.107670
Marisa Saenz Leme

Soberania e fiscalidade no Brasil independente: concepç̃es da imprensa paulista

O verdadeiro Liberal, amigo da ordem das Leis, e do seu paiz não se curva diante da iniquidade, advoga os direitos dos outros homens, e a causa da razão, ainda que assim desagrade ao Poder; mas foge de toda a violencia, de toda a perfidia, e dos meios infames, e illegaes. O falso Liberal, em quanto mesmo representa o seu papel de Theatro, vocifera, é certo, contra os do Governo, porem quasi sempre com paixão, deixa transluzir a parcialidade, e ma-fé... O primeiro, inabalavel na conducta, porque é filha da convicção intima, não pergunta o nome do homem, que está no Ministerio; mas sim quaes são as suas acções, e systema politico; o segundo informa-se cuidadosamente, não só do nome do actual Ministro, porem ainda do que está próximo a substituil-o, e segundo esse thermometro gradua o calor, ou o frio das suas palavras. ${ }^{27}$

Ao dar visibilidade para a imagem dos liberais frente a um público mais amplo, a defesa da legalidade era invocada como seu apanágio. Aqueles que seriam contra as instituições de governo em si não seriam os verdadeiros liberais, mas oportunistas, capazes de serem seduzidos pelas benesses dos poderosos de momento. Já próximo à Abdicação, expunha-se n'O Observador Constitucional:

As leis (...) são as bases sobre que repousão a ordem social, a tranquillidade publica, a prosperidade da patria, e a ventura dos Cidadãos. São um dique, contra o qual vêm partir-se os esforços do malvado, uma barreira que protege os homens de bem, e lhes afiança a vida, a honra, a propriedade. Sem ellas tudo entraria outra vez no cahos, as paixões desenvreadas encherião tudo de confuzão, perturbações e desordem; a inveja, a cúbica, o odio, e a vingança exercerião livremente os seus furores; o pobre quereria despojar o rico; o preguiçoso apoderar-se dos fructos do trabalho do homem activo e industrioso, o immoderado aproveitar as economias do homem sobrio (...) a anarchia em fim houvera destruido bem depressa todos os elementos da ordem, e refundido o Corpo social n'um abismo de males, que trarião de novo a barbaridade, e quase a extincção da especie humana. ${ }^{28}$

Simultaneamente à condenação da "anarchia", insistia $O$ Observador Constitucional, nos críticos anos de 1829, à Abdicação, na defesa da "liberdade individual": ordem e liberdade constituíam faces de uma mesma moeda. N'O Farol Paulistano, a par de vários artigos versando sobre a defesa em si da Constituição, não sendo esta "uma simples palavra, mas uma cousa", proclamava-se "a coragem civil", e tratava-se "da Liberdade", da "Liberdade Constitucional em Geral", das "várias esferas da liberdade" e "das liberdades consti-

\footnotetext{
${ }^{27}$ Idem, 25-10-1828. Era comum a transcrição, tanto n'O Farol Paulistano como n'O Observador Constitucional, de artigos de outros periódicos, nacionais e estrangeiros.

${ }^{28}$ O Observador Constitucional, 25-02-1831. Note-se que, nesse momento, o jornal já estava sob nova direção, após o assassinato de Líbero Badaró.
} 
tucionaes", associadas às "liberdades religiosas". Para a pregação doutrinária dos ideais de liberdade, utilizavam-se abundantemente artigos desenvolvidos pelos ideólogos iluministas e liberais, como, por exemplo, as "reflexões sobre a liberdade" de mme. De Stäel.

Nesse quadro conceitual, o termo "representativo", na concepção ideal de estado/governo apresentada pelos liberais paulistas, compreendia a soberania popular aos moldes do que se consagrou na superação política liberal do iluminismo, afirmando-se como seu princípio básico a representação política, em vez do seu exercício direto, como queria Rousseau. Logo no segundo número afirmava-se n'O Farol Paulistano de 14-02-1827 que o "povo nunca exerceu direccta e realmente a soberania, mas sempre a conferio...." ${ }^{29}$ A representação política, tal qual era concebida no Estado liberal, seria a melhor opção para solucionar o dilema colocado entre o mando de um só ou o mando popular direto, que geraria a anarquia. Na representação, estabelece-se o mando popular indireto, garantindo-se a sua soberania na ordem.

Esposando uma concepção de soberania coerente com os princípios liberais, o entendimento da monarquia representativa, em suas possibilidades efetivas de funcionamento, remetia também a formulações sobre a "opinião publica", parcialmente compreendida como "a soma de todos os negocios particulares". Os "Cidadãos" deveriam tomar parte nos negócios da nação e da Província. Logo no seu número inaugural, exortava-se, n'O Farol Paulistano, os paulistas a tomarem "interesse e parte nos negocios da Nação e da Provincia, que são o vosso proprio negocio tanto ou mais do que vossas lavouras e de que vossas mercancias". No mais puro espírito da filosofia utilitarista, aproximava-se a noção de "patria" à vivência da felicidade, ${ }^{30}$ considerando-se ainda que a "felicidade de cada um era igual á felicidade da nação". ${ }^{31}$

Ordem, liberdade e negócios públicos eram elementos que se articulavam num todo coerente em defesa do Estado liberal burguês, no caso, na sua forma monárquica constitucional. É de salientar que ambos os periódicos defendiam a formação de sociedades particulares, em diversos níveis, para a implementação econômica ou de ação beneficente, tal qual existiam nos Estados Unidos da América e na Inglaterra. Elogiava-se a associatividade, asseverando-se que "o espirito d'associação, indispensavel nos governos livres, tem progredido no Brasil". Em São Paulo, afirmava-se, havia "varias socieda-

\footnotetext{
${ }^{29}$ Farol Paulistano, 14-02-1827.

${ }^{30}$ Idem, 01-09-1827.

31 Idem, 29-08-1827.
} 
des aparecidas em differentes partes desta Provincia". ${ }^{32}$ Complementava-se o entendimento de "publico" com a definição do papel da imprensa: a defesa do "interesse geral", pensado em termos da "opinião publica". Afirmava-se a compreensão da imprensa como civilizadora, com a obrigação da transparência.

No campo conceitual desenvolvido nos jornais avaliados, a defesa da liberdade dentro da ordem, a recorrente aproximação entre opinião pública e negócios e a correlata importância das instituições de governo, provocam a indagação: como foi pensada, pelos liberais moderados paulistas, a questão do controle financeiro a ser exercido pelo governo central? Essa questão, como se discorrerá a seguir, foi fundamental para a constituição soberana do estado moderno.

\section{Entre absolutismo e liberalismo, a fiscalidade nas concepções da soberania estatal}

Conforme a literatura especializada, ${ }^{33}$ a construção da soberania estatal a partir de fins da Idade Média e início da chamada Idade Moderna - redundando na formação do Estado absolutista - implicou o desenvolvimento da capacidade de controle, por parte do núcleo central do estado, da arrecadação de impostos, bem como da institucionalização da violência. Como essas questões se apresentaram no Estado liberal? Trata-se de uma temática crucial para o entendimento das relações sociedade-estado nesse contexto. Muitas vezes, ao se apresentar o Estado liberal como um contraponto do absolutismo, dirimem-se essas temáticas, acentuando-se os aspectos de constitucionalidade, divisão dos poderes, liberdade individual e de imprensa que deram o tônus político liberal contra o Antigo Regime. Contudo, no âmbito dos pressupostos do liberalismo - em que pese a transformação profunda das bases sociopolíticas do Antigo Regime -, manteve-se, na reestruturação do Estado

\footnotetext{
32 O Observador Paulistano, 04-03-1831.

${ }^{33}$ Conceitos sobremaneira desenvolvidos nas seguintes obras: ELIAS, Norbert. O processo civilizador, $2^{\circ}$ vol. Formação do estado e civilização. Rio de Janeiro: Jorge Zahar Ed., 1993; TILLY, Charles (ed.). The formation of the national states in western Europe. Princeton, Nova Jersey, USA: Princeton University Press, 1975. HABERMAS, Jürgen. Mudança estrutural da esfera pública. Rio de Janeiro: Edições Tempo Brasileiro, 1984.
} 
rev. hist. (São Paulo), n. 173, p. 277-302, jul.-dez., 2015 http://dx.doi.org/10.11606/issn.2316-9141.rh.2015.107670
Marisa Saenz Leme

Soberania e fiscalidade no Brasil independente: concepcões da imprensa paulista

então ocorrida, a soberania do seu núcleo central, com base nesses mesmos controles que foram conceituados como monopólios fiscal e da violência. ${ }^{34}$

Tratando-se da natureza do Estado no Brasil independente, essas temáticas ganharam contornos mais complexos, tendo-se vivenciado o absolutismo sob o estatuto colonial da América portuguesa, seguindo-se, nas duas primeiras décadas do século XIX, o convívio direto com o centro do poder metropolitano estabelecido no Rio de Janeiro. ${ }^{35}$

A presença da Corte no Brasil, num período de desenvolvimento dos interesses "brazilienses", 36 se, de um lado, possibilitou a vivência direta da centralidade estatal absolutista, de outro, contribuiu para o amadurecimento de uma reflexão política matizada sobre a natureza do Estado, o que pode ter levado a outras percepções a respeito da sua centralidade. Dessa forma, durante o processo de Independência e no $1^{\circ}$ Império, concomitantemente à vociferação, de modo subsequente, contra o absolutismo português, a recolonização pretendida pelas Cortes e o "absolutismo" de d. Pedro, apresentavam-se conceitos que indicavam a necessidade da construção dos monopólios fiscais e da violência, para a existência de uma devida soberania estatal. ${ }^{37}$

Os posicionamentos a respeito dos controles fiscais e armados se articularam, naturalmente, às construções/concepções mais gerais de Estado que se apresentaram no período das independências americanas. Um caso clássico foi a discussão a respeito do assunto entre federalistas e os defensores da confederação, no momento da construção inicial dos Estados Unidos da América. ${ }^{38}$ No que se refere à ex-América portuguesa, os posicionamentos

\footnotetext{
${ }^{34}$ ELIAS, Norbert. $O$ processo civilizador, $2^{\circ}$ vol. Formação do estado e civilização, op. cit., 1993, capítulo 2: Sobre a sociogênese do Estado. Para a fiscalidade ver, sobretudo, o item VIII: Sobre a sociogênese do monopólio de tributação. Também para a fiscalidade destaque-se: ARDANT, Gabriel. Financial policy and economic infraestructure of modern states and nations. In: TILLY, Charles (ed.). The formation of the national states in western Europe, op. cit., 1975, cap. 3.

35 Ver para a temática: OLIVEIRA, Cecília Helena de Salles. A astúcia liberal. Bragança Paulista: Edusf/ Ícone, 1999; MALERBA, Jurandir. A corte no exílio: civilização e poder no Brasil às vésperas da Independência (1808 a 1821). São Paulo: Companhia das Letras, 2000.

${ }^{36}$ Trata-se de um período formativo do que viria a se considerar como uma identidade brasileira, enquanto distinção entre portugueses americanos e metropolitanos. Nesse sentido, foi paradigmática a expressão utilizada por Hipólito José da Costa no título do seu famoso jornal, editado em Londres entre 1808 e 1822, em defesa do que concebia como os interesses do Brasil no contexto do Reino Unido de Portugal, Brasil e Algarves: Correio Braziliense.

${ }^{77}$ Para essas temáticas durante o processo de Independência, ver: LEME, Marisa Saenz. Soberania, centralização, federação e confederação no discurso jornalístico da Independência: a visão de O Conciliador Nacional. RIHGB, v. 440, jul./2009, p. 29-62.

${ }^{38}$ Para tanto ver: HAMILTON, MADISON, JAY. The federalist papers. Nova York: Mentor, 1999.
} 
sobre os referidos monopólios variaram de acordo com a gama dos projetos políticos para o país em construção, havendo que considerar, ainda, a ampla diversidade regional em que teoria e prática políticas foram vivenciadas nas diversas partes daquele Brasil em formação. Partes cuja unidade, ainda na segunda metade do século XVIII, tinham sua expressão apenas a partir da ótica metropolitana.

Esses projetos - que, surgidos no próprio processo de Independência, estenderam-se pelo $1^{\circ}$ Império e além deste ${ }^{39}$ - impulsionaram a discussão historiográfica a respeito do seu sentido, no que se refere ao seu teor liberal, federativo, centralista, absolutista ou simplesmente autoritário. Contudo, são poucos os trabalhos elaborados sobre a relação entre o desenvolvimento dos monopólios fiscal e da violência e a construção da soberania do Estado brasileiro.

Por sua vez, os estudos existentes sobre a temática dedicaram-se sobretudo às construções institucionais em si. Nesse sentido, em relação à fiscalidade, destacam-se os trabalhos de Wilma Peres Costa. ${ }^{40}$ De um lado, a autora tratou da questão no período entre finais do século XVIII e a Independência; de outro, estendeu-se sobre a segunda metade do século XIX. Com base sobretudo nos referenciais teóricos a respeito da construção do Estado elaborados por Charles Tilly, estudou ela as relações entre a institucionalização fiscal e os mecanismos de controle do poder central, avaliando a aplicabilidade dos conceitos de tax state e de dominium state, de acordo com os preceitos de Schumpeter. Correspondendo o primeiro à forma de institucionalização dos impostos no liberalismo e o segundo no absolutismo, a autora avalia que teria predominado, no Brasil do século XIX, o dominium state, mesmo que tenha havido uma tentativa de desenvolver fiscalidade com base no tax state. Nesse contexto, não teria efetivamente evoluído uma soberania central no estado monárquico.

\footnotetext{
39 Para uma discussão bastante matizada da evolução dos posicionamentos políticos que se apresentaram no Rio de Janeiro no início do $1^{\circ}$ Império ver: NEVES, Lúcia Maria Bastos Pereira das. Corcundas e constitucionais: a cultura política da Independência (1820-1822). Rio de Janeiro: Revan/ Faperj, 2003. OLIVEIRA, Cecília Helena de Salles. A astúcia liberal - Relações de mercado e projetos políticos no Rio de Janeiro (1820-1824). Bragança Paulista: Edusf/ Ícone, 1999. SLEMIAN, Andréa. Vida política em tempo de crise: Rio de Janeiro, 1808-1824. São Paulo: Hucitec, 2004.

${ }^{40}$ COSTA, Wilma Peres. O Império do Brasil: dimensões de um enigma. Almanack Braziliense, São Paulo, mai/2005; COSTA, Wilma Peres. Do domínio à nação, impasses da fiscalidade no processo de Independência. In: JANCSÓ, István (org.). A formação do Estado e da nação brasileira, v. 1. São Paulo: Hucitec, 2003, p. 143-194.
} 
Num outro diapasão, Adauto Franciozo Diniz ${ }^{41}$ conclui por uma progressiva imposição da soberania central por intermédio da fiscalidade. Seu estudo inicia-se em 1830, no final do $1^{\circ}$ Império, portanto. Na avaliação do autor, já se observa, nesse momento, a existência de uma fiscalidade soberana e moderna.

Tendo essa discussão como um quadro de referência fundamental, meu objetivo no presente texto não é, contudo, o de avaliar a efetividade da institucionalização no Brasil independente de um ou outro tipo de atuação fiscal por parte do Estado. Antes, direciono-me para o estudo do pensamento das elites a respeito da questão, em que se distingue, em primeiro lugar, o fator da centralização do poder fiscal num núcleo soberano do Estado em si, independentemente de tratar-se do tax ou do dominium.

Tomando-se por base, na compreensão das relações sociedade-estado, que o domínio público, no estado liberal, no reverso do absolutismo, se construiu a partir da ótica do mundo privado, ${ }^{42}$ pode-se, num primeiro momento, conceber que, também no reverso do absolutismo, o novo Estado não se imporia, entre outros fatores, a partir dos monopólios fiscal e da violência. Ledo engano. Uma vez surgido e fortalecido com a crise política do feudalismo, o Estado central impôs-se com dinâmica própria sobre as partes que o compunham e não se desfez com o liberalismo. Pelo contrário, essa centralidade foi reafirmada e atuada no Estado liberal, quer tenha ele adquirido, para citar os exemplos extremados, a forma federativa, como nos Estados Unidos da América, ou centralizada, como na França.

Tendo o abuso na instituição e cobrança dos impostos se tornado um dos polos de revolta contra a opressão estatal exercida no Antigo Regime, a instituição do monopólio fiscal no Estado liberal naturalmente se deu a partir de um conjunto de controvérsias, quer nos países em que se gestou teoricamente o liberalismo, quer nas antigas colônias. No Brasil do $1^{\circ}$ Império, a revolta contra o que pudesse lembrar a situação colonial misturava-se à necessidade de construção de um novo Estado, em cuja base social apresentava-se ainda, diferentemente dos países de formação do liberalismo clássico, um fator socioeconômico chave: a dependência da mão de obra escrava para o adequado funcionamento dos setores de ponta, numa economia de base exportadora.

\footnotetext{
${ }^{41}$ DINIZ, Adauto Franciozo. Centralização política e concentração de riqueza: as finanças do Império brasileiro no período de 1830 a 1889. Revista da BBS Business School, vol. 1, n. 1, 2º sem. 2005.

${ }^{42}$ HABERMAS, Jürgen. Mudança estrutural da esfera pública. Rio de Janeiro: Edições Tempo Brasileiro, 1984.
} 
Nesse contexto, a construção do Estado no Brasil independente, tendo um imperador bragantino como chefe do executivo, confundiu muito os contemporâneos, ao menos no nível da retórica. As medidas fiscais e militares de d. Pedro I podiam assim receber o epíteto de "absolutistas", quando, problematiza-se, estava-se construindo, pela primeira vez, uma soberania estatal específica àquele território, agora no contexto do liberalismo. ${ }^{43}$

Com base nas considerações acima, procuro, neste texto, captar os entendimentos a respeito da instituição e cobrança dos impostos, verificáveis nos jornais paulistas durante o $1^{\circ}$ Império. Entendimentos esses que estariam indicando, ou não, a adesão dessas elites ao que veio a se configurar teoricamente como "monopólio fiscal" por parte do Estado soberano.

\section{A construção dos entendimentos de controle financeiro entre as elites paulistas}

Em São Paulo, no momento inicial da montagem do governo de d. Pedro I - em que pese o notório apoio da Província ao regente e depois imperador - resistia-se à concentração financeira no Estado em formação. Na primeira Junta de Governo da Província, organizada a partir da reordenação político-administrativa decorrente da Revolução do Porto, protestava-se "obedecer a d. Pedro" em todos os aspectos necessários, "menos no que toca a mandar dinheiro". ${ }^{44}$ Resistência essa que, embora se manifestando nas posturas iniciais do Conselho da Presidência, foi-se atenuando paulatinamente. Ao mesmo tempo em que se impunha na Província o controle administrativo e financeiro sobre os municípios, observava-se a flexibilização das concepções financeiras em relação ao governo central, admitindo-se a sua soberania, no decorrer dos debates ocorridos, sobretudo, no Conselho Geral da Provín-

\footnotetext{
${ }^{43} \mathrm{Na}$ historiografia sobre o $1^{\circ}$ Reinado predominou a interpretação do governo de d. Pedro I como "absolutista" ou, na melhor das hipóteses, extremamente autoritário, tratando-se de modo subordinado outros elementos formativos da realidade política de então, como a história institucional e a participação legislativa. É o que atualmente se revisa na historiografia sobre esse período. Para uma excelente síntese do "estado da arte" em relação a essa temática, ver: MARSON, Izabel Andrade $\mathcal{E}$ OLIVEIRA, Cecília H. de S. (org.). Introdução. Monarquia, liberalismo e negócios no Brasil: 1780-1860. São Paulo: Edusp, 2013.

${ }^{44}$ Conforme relatado por d. Pedro em carta ao pai, de 17 de julho de 1821. Citado em RIZZINI, Carlos. Hipólito da Costa e o Correio Braziliense. São Paulo: Companhia Editora Nacional, 1957, p. 254.
} 
rev. hist. (São Paulo), n. 173, p. 277-302, jul.-dez., 2015 http://dx.doi.org/10.11606/issn.2316-9141.rh.2015.107670
Marisa Saenz Leme

Soberania e fiscalidade no Brasil independente: concepcões da imprensa paulista

cia. ${ }^{45}$ Posturas essas que se evidenciaram também na imprensa paulista do período.

Sendo um tema recorrente nos periódicos em apreço, o tratamento da questão financeira diferenciava-se entre os planos provincial e nacional. Por sua vez, no que se refere ao governo central, distinguiam-se os poderes Legislativo e Executivo nas atribuições de legislação e controle financeiros.

Significativa da postura continuamente assumida no âmbito provincial, O Farol Paulistano, desde o início da sua publicação, colocava a fiscalização no sentido do acompanhamento crítico das finanças da Província - como um dos objetivos principais a ser perseguido pelo jornal. Afirmava-se no periódico ser "nosso principal desvelo os interesses peculiares desta Província, fixando mui particularmente nossas vistas sobre as rendas publicas, e negócios a ella pertencentes". Nesse sentido, advertia-se que a Junta da Fazenda deveria ser composta por membros "em que devemos confiar, e de cujo patriotismo e probidade não duvidamos". ${ }^{46}$

Diferenciava-se o tom em relação ao plano nacional, na medida em que os jornais eram contrários à elevação dos impostos, mas, simultaneamente, atribuíam ao governo central, na sua dimensão legislativa, a legitimidade de instituí-los. Entre elaboração legislativa e fiscalização ordinária/cotidiana, afirmava-se a soberania do estado-nação, em consonância com os direitos da cidadania, num argumentação típica do liberalismo clássico. ${ }^{47}$

Numa série de matérias, combateu-se nos jornais a cobrança do que eram considerados impostos extorsivos. Referindo-se à "Nação exaurida de tanto pagar" afirmava-se em $O$ Farol Paulistano o seu direito a "não querer mais pagar" ${ }^{48}$ Considerava-se que os impostos afogavam a indústria. ${ }^{49}$ Em fins de 1829, quando se acirrava ainda mais a oposição ao Executivo, acusavam-se os "jornais extrangeiros", ou seja, aqueles produzidos no Brasil por estrangeiros vinculados ao imperador, de proporem o aumento dos impostos. ${ }^{50}$

\footnotetext{
${ }^{45}$ Para a evolução desse posicionamento, ver: LEME, Marisa Saenz. Dinâmicas centrípetas e centrífugas na formação do Estado monárquico no Brasil: o papel do Conselho Geral da Província de São Paulo. Revista Brasileira de História, v. 28, 2008, p. 197-215.

${ }^{46}$ O Farol Paulistano, 22-08-1827.

47 Para tanto, ver: LOCKE, John. Segundo tratado sobre o governo, cap. IX. Dos fins da sociedade política e do governo. Locke. São Paulo: Nova Cultural, 1991 (Coleção Os Pensadores); MONTESQUIEU. O espírito das leis. $2^{\mathrm{a}}$ parte, Livro XII. Das leis que constituem a liberdade política, em sua relação com o cidadão. São Paulo: Martins Fontes, 1996.

48 O Farol Paulistano, 14-11-1827.

${ }^{49}$ Idem, 27-06-1829.

${ }^{50}$ Idem, 02-05-1829.
} 
Em novembro de 1830, já bem próximo à Abdicação, tratava insistentemente $O$ Observador Constitucional dos malefícios causados pelos abusos na instituição e cobrança de impostos, o que, muitas vezes, teria levado à exasperação revolucionária. Chegava-se mesmo a comparar o então contexto do Império com situações vividas na relação colônia/colonizador: "Muitas revoluçõesforãofeitasporcausa dasfinanças, principiandopeladosEstados Unidos..." 51

Mas os exemplos apresentados nesse periódico remetiam também à situação do Estado liberal e ao reforço do Legislativo. Dessa maneira, explicava-se a Revolução Francesa de 1830: a revolta contra os impostos teriam sido o "primeiro sinal" da "ultima revolução francesa", consubstanciado na "resolução dos principaes contribuintes Franceses de não pagarem os tributos não consentidos pela Camara dos Deputados". ${ }^{52}$ Ou seja, em relação aos impostos, legitimava-se a ação legislativa em detrimento do Executivo.

Por sua vez, ao mesmo tempo em que se propunham taxas as menores possíveis, afirmava-se a necessidade de uma regulamentação financeira nacional, por intermédio da elaboração, ano a ano, de uma pauta orçamentária. O que se considerava imprescindível para uma adequada arrecadação dos impostos:

He doutrina bem sabida, que não precisa de commentarios, e pela nossa Constituição reconhecida, que sem lei de orçamento, sem fixação de despezas, sem decretação annual dos impostos, não existem despezas, não se pode arrecadar tributos, e os cidadãos não são obrigados a pagal-os, e nenhuma força pode lh'os arrancar...

Prosseguia a matéria com o exemplo nesse sentido dado pelos "paises constitucionaes", defendendo-se a "lei de orçamento" em termos nitidamente condizentes com as concepções da relação sociedade-estado vigentes no liberalismo clássico:

Se dar o que he seu he sempre hum sacrificio, he necessário para ser justo que tenha o fim que se propoz o que o fez; empregado em outros fins he ladroeira. Qual o fim que se propõem cada homem na sociedade? Ser julgado, governado, deffendido, etc. Mas entrará talvez na cabeça a alguém de pagar alguma coisa para manter o luxo de hum,

\footnotetext{
${ }^{51}$ O Observador Constitucional, 22-11-1830.

52 Idem, 08-11-1830.
} 
rev. hist. (São Paulo), n. 173, p. 277-302, jul.-dez., 2015 http://dx.doi.org/10.11606/issn.2316-9141.rh.2015.107670
Marisa Saenz Leme

Soberania e fiscalidade no Brasil independente: concepcões da imprensa paulista

ou muitos individuos, para fazer passar outros em sancto ócio? Será possivel que alguem queira pagar caro hum serviço que pode obter igualmente bem feito, e mais barato?

Por causa de tudo isto he que a Lei do Orçamento nos Governos constitucionaes, he chamada Lei das Leis, e considerada como a mais importante de todas porque d'ella todas as outras dependem. ${ }^{53}$

Por intermédio do Legislativo, a transparência na elaboração do orçamento e a fiscalização do seu cumprimento constituiriam elementos fundamentais para o exercício de uma cidadania com base na valorização do indivíduo e da propriedade, justificando-se por esse caminho a legitimidade do governo central no exercício da sua soberania.

Toda a existencia da sociedade depende desta lei, que a Nação incumbiu aos seus representantes (...) Os serviços publicos são indispensáveis (...) O orçamento determina quaes são os serviços de que a Nação precisa, e estes se devem fazer, quaes são os de que não precisa mais, e estes se devem cortar. O orçamento empede que o dinheiro publico entre nas algibeiras particulares (...) Eis a importancia do Orçamento ao qual tudo esta ligado, e sem o qual não há liberdade, não há propriedade, porque o Cidadão he obrigado a dar sem saber porque, o governo pode gastar para si e não para o Cidadão... ${ }^{54}$

No contexto de oposição ao governo de d. Pedro I, a defesa da Lei do Orçamento implicava diretamente no controle das ações do Ministério, evitando-se a "ladroeira" que se imputava a esse campo. Estendendo-se sobre o mal decorrente para o país de se entrar num novo ano sem orçamento aprovado, responsabilizava-se nesse sentido a demora do Senado em votar o que já fora aprovado na Câmara, postura essa que decorreria das "manhas da facção aristocratica", ou seja, daquela parte do Legislativo considerada em conluio com o Ministério. ${ }^{55}$

Da mesma forma, a valorização da Câmara dos Deputados, em detrimento do Senado e do executivo ministerial, apresentava-se no tocante à relação financeira entre Província e governo central. Aplaudindo a deliberação da primeira em abolir o exclusivo do porto de Santos para a comercialização

\footnotetext{
53 Idem, 12-11-1830.

54 Idem.

55 Idem, 08-11-1830. Posicionamento esse sintonizado com as posturas de combate ao Senado feito pela oposição liberal durante o $1^{\circ}$ Império. Para tanto ver, entre outros: CUNHA, Pedro Otávio da. A fundação de um império liberal. In: História geral da civilização brasileira, tomo II, $1^{\circ}$ vol. $6^{\text {a }}$ edição. São Paulo: Difel, 1985; MONTEIRO, Tobias. História do Império: o Primeiro Reinado, vol. 41. Belo Horizonte: Itatiaia; São Paulo: Edusp. (Coleção Reconquista do Brasil)
} 
marítima dos produtos da Província, ataca-se o absolutismo governamental e o que se considerava a "aristocracia" do Senado, contrapondo-os ao que era avaliado como a efetiva representação nacional da Câmara dos Deputados.

De um lado, a permanência durante o Império do exclusivo de origem colonial teria sido "conservada pelo privilégio de sempiternidade que tem todos tributos nos governos absolutos...". Citava-se Montesquieu, declarando como "os máos govêrnos querendo dinheiro para mal gastarem impõem pesados tributos..." que afogam as possibilidades produtivas de uma nação. Nesse contexto,

a Camara dos Deputados, grandemente sollicita em promover o bem dos seus constituintes, não deixa de aproveitar todas as ocasiões de afastar alguns dos muitos obstáculos, com que entorpercerão a Nação o Systema Colonial, os Bachás, e o regime absoluto antigo; mas não é só nas mãos dos Deputados que estão os nossos destinos; e esta Provincia tão afortunada tem sido na Camara dos Deputados quanto desgraçada na dos Senadores (...) mas que querem se os Deputados são plebeos como o resto da Nação e os Senadores aristocratas como elles sozinhos?...

No âmbito das posturas apresentadas nos periódicos em relação aos poderes de estado, frise-se, porém, a diferenciação feita entre Poder Executivo, na figura do Ministério, e Poder Moderador, exclusivo do imperador. Dessa forma, O Observador Constitucional, ao tratar das posturas envolvidas na referida proposta orçamentária para o ano de 1831, avaliou positivamente o Poder Moderador, atribuindo-lhe o sentido pensado por Benjamin Constant para o "poder real". 57

A posição extraordinária do Brazil, por causa das manhas da facção aristocratica, foi perfeitamente bem entendida pelo Poder Moderador, o qual fez o quanto estava á seu alcance para que a conclusão final do orçamento tivesse lugar (...) Fez quanto estava a seu alcance o Poder Moderador, porque nada mais lhe era concedido pela Constituição, que lhe não concede a faculdade de interpretar as leis secundarias e por isso ainda menos a fundamental, e apesar de que a Constituição conceda ao Poder Moderador

\footnotetext{
${ }^{56}$ O Farol Paulistano, 17-11-1827, n. 65.

${ }^{57}$ Para tanto ver: CONSTANT, Benjamin. Príncipes de politique. In: Idem. Écrits politiques. Paris: Gallimard, 1997.
} 
velar ao equilíbrio e harmonia dos mais poderes politicos, além de que a questão verte não entre dois Poderes, mas entre duas facções do mesmo Poder...58

Já bem próximo da Abdicação, o poder de estado envolvido no Poder Moderador e, nele, a atuação de d. Pedro I, eram matérias de encômios por parte do jornal. A ação do governo central, na sua própria dimensão executiva, também era valorizada nos periódicos em apreço em relação a outros planos financeiros. De modo constante, colocaram-se contra a extinção do Banco do Brasil; ${ }^{59}$ por sua vez, valorizavam os empréstimos a serem feitos entre particulares e governo central. Acompanharam ainda criticamente a questão das moedas falsas, produzidas na Bahia e em Goiás: pedia-se forte ação do Estado central no sentido de se garantir a efetiva circulação apenas de uma única moeda nacional.

A perspectiva apresentada pelos "liberais moderados" na Província de São Paulo, retratada nos jornais aqui analisados, era a de uma centralização que normalizasse as finanças nacionais, minuciosamente acompanhadas em seus diversos aspectos, com publicação e análise das decisões do governo central, quer no nível do Executivo, quer do Legislativo. Nesse contexto, evoluíram para validar a soberania do Estado em formação, no que se refere ao controle fiscal.

Ao mesmo tempo em que se procurava poupar o bolso do contribuinte e defender as finanças provinciais - acusando-se a improbidade administrativa do governo de d. Pedro I - propugnava-se pela existência organizada das finanças nacionais, no sentido da construção do que veio a se conceituar como "monopólio fiscal" por parte do Estado soberano. Mas em sua dimensão liberal, com ênfase no controle legislativo sobre a questão.

Em harmonia com essa concepção de Estado, depreende-se claramente dos posicionamentos dos "moderados" paulistas uma postura favorável ao estabelecimento do tax state, nos moldes claramente liberais, na contramão do dominum state. Ou seja, postulava-se um Estado soberano, com base numa centralidade que se impunha às partes que o constituíam. Para tanto, era fator fundamental a capacidade de se manter um fluxo financeiro regular, por intermédio, entre outros fatores, da cobrança de impostos a recaírem sobre os indivíduos e suas propriedades.

\footnotetext{
${ }^{58}$ O Observador Constitucional, 10-12-1830.

59 Para a questão do Banco do Brasil no Parlamento ver: ALVES, João Victor Caetano. A Câmara na Coroa: ascensão e queda do gabinete de novembro de 1827. São Paulo: Unesp edições, texto on-line, 2013.
} 
Dessa forma, nas matérias dos jornais paulistanos do $1^{\circ}$ Reinado, aplaudia-se o fim dos privilégios e contratos fiscais advindos da governança colonial, ao mesmo tempo em que se defendia uma racionalidade fiscal por parte do Estado centralizado. Por intermédio da valorização do Legislativo, instava-se a sociedade a acatar esse tipo de comando soberano. Conforme Habermas, ${ }^{60}$ com o advento do Estado liberal, a esfera pública, em grande parte consubstanciada no Parlamento, passou a ser dirigida, na contramão do Estado absolutista, a partir da esfera privada, constituindo-se assim contraditoriamente o liberalismo, desde os seus primórdios, entre as suas dimensões pública e privada, entre um discurso descentralizador e o Estado impositivo. A avaliação das concepções apresentadas pelos moderados paulistas indica a sua particular inserção, com posicionamentos claramente definidos no campo liberal, no sentido das formulações desenvolvidas pelo filósofo alemão.

\section{Fontes primárias}

AEL - Arquivo Edgard Leuenroth. O Farol Paulistano (fev/1827 a abr/1831). O Observador Constitucional (out/1829 a abr/1831). Centro de Pesquisa e Documentação Social. Instituto de Filosofia e Ciências Humanas, Unicamp.

\section{Referências bibliográficas}

ALVES, João Victor Caetano. A Câmara na Coroa: ascensão e queda do gabinete de novembro de 1827. São Paulo: Unesp edições, texto on-line, 2013.

ARDANT, Gabriel. Financial policy and economic infraestructure of modern states and nations. In: TILLY, Charles (ed.). The formation of the national states in western Europe. Princeton, Nova Jersey, USA: Princeton University Press, 1975.

AMARAL, Antônio Barreto do. Dicionário de história de São Paulo. São Paulo: Governo do Estado, 1980.

BASILE, Marcelo. Projetos de Brasil e construção nacional na imprensa fluminense (1831-1835). In: NEVES, Lúcia Maria Bastos P. ; MOREL, Marco; FERREIRA, Tania Maria Bessone da C. História e imprensa: representações culturais e práticas de poder. Rio de Janeiro: Faperj/DP \& A editora, 2006.

CONTIER, Arnaldo. Imprensa e ideologia em São Paulo (1822-1842). São Paulo: Vozes, 1979.

CONSTANT, Benjamin. Écrits politiques. Paris: Gallimard, 1997.

\footnotetext{
${ }^{60}$ HABERMAS, Jürgen. Mudança estrutural da esfera pública: investigações quanto a uma categoria da sociedade burguesa, op. cit., 1984.
} 
rev. hist. (São Paulo), n. 173, p. 277-302, jul.-dez., 2015 http://dx.doi.org/10.11606/issn.2316-9141.rh.2015.107670
Marisa Saenz Leme

Soberania e fiscalidade no Brasil independente: concepcões da imprensa paulista

COSTA, Wilma Peres. Do domínio à nação, impasses da fiscalidade no processo de Independência. In: JANCSÓ, István (org.). A formação do Estado e da nação brasileira, v. 1. São Paulo: Hucitec, 2003, p. 143-194.

COSTA, Wilma Peres. O Império do Brasil: dimensões de um enigma. Almanack Braziliense, São Paulo, mai/2005.

CUNHA, Pedro Otávio da. A fundação de um império liberal. In: História geral da civilização brasileira, tomo II, $1^{\circ}$ vol. $6^{\text {a }}$ edição. São Paulo: Difel, 1985.

DELATORRE, Aparecida Vanessa. São Paulo à época da Independência. Contribuição para $o$ estudo do chamado movimento "bernardista", 1821/1823. Dissertação de mestrado, FFLCH-USP, dez/2003.

DINIZ, Adauto Franciozo. Centralização política e concentração de riqueza: as finanças do Império brasileiro no período de 1830 a 1889. Revista da BBS Business School, vol. 1, n. 1, $2^{\circ}$ sem. 2005.

ELIAS, Norbert. $O$ processo civilizador, $2^{\circ}$ vol. Formação do estado e civilização. Rio de Janeiro: Jorge Zahar Editor Ltda., 1993.

FREITAS, Affonso A. de. A imprensa periódica de São Paulo desde os seus primórdios em 1823 até 1914. Separata da Revista do Instituto Historico e Geographico de São Paulo, vol. XVI. São Paulo, Typ. do "Diario Official", 1915.

HABERMAS, Jürgen. Mudança estrutural da esfera pública: investigações quanto a uma categoria da sociedade burguesa. Rio de Janeiro: Edições Tempo Brasileiro, 1984.

HAMILTON; MADISON; JAY. The federalist papers. Nova York: Mentor, 1999.

LEME, Marisa Saenz. Dinâmicas centrípetas e centrífugas na formação do Estado monárquico no Brasil: o papel do Conselho Geral da Província de São Paulo. Revista Brasileira de História, v. 28, no 55, jan.-jun. 2008.

Soberania, centralização, federação e confederação no discurso jornalístico da Independência: a visão de $O$ Conciliador Nacional. R IHGB, a. 169, n. 440, jul./set. 2008, p. 25.

São Paulo no $1^{\circ}$ Império: poderes locais e governo central. In: OLIVEIRA, Cecília Helena de Salles; PRADO, Maria Ligia Coelho; JANOTTI, Maria de Lourdes Mônaco. (org.). A história na política, a política na história. São Paulo: Alameda/Programa de Pós-Graduação em História Social USP, 2006.

LOCKE, John. Segundo tratado sobre o governo. Cap. IX. Dos fins da sociedade política e do governo. Locke. São Paulo: Nova Cultural, 1991. (Coleção Os Pensadores)

MALERBA, Jurandir. A corte no exílio: civilização e poder no Brasil às vésperas da Independência (1808 a 1821). São Paulo: Companhia das Letras, 2000.

MARSON, Izabel Andrade $\mathcal{E}$ OLIVEIRA, Cecília H. de S. (org.). Introdução. Monarquia, liberalismo e negócios no Brasil: 1780-1860. São Paulo: Edusp, 2013.

MONTEIRO, Tobias. História do Império: O Primeiro Reinado, vol. 41. Belo Horizonte: Itatiaia; São Paulo: Edusp. (Coleção Reconquista do Brasil)

MOREL, Marco. As transformações dos espaços públicos: imprensa, atores políticos e sociabilidades na cidade imperial (1820-1840). São Paulo: Hucitec, 2005.

MONTESQUIEU. O espírito das leis, 2a parte. Livro XII. Das leis que constituem a liberdade política em sua relação com o cidadão. São Paulo: Martins Fontes, 1996. 
NEVES, Lúcia Maria Bastos Pereira das. Corcundas e constitucionais: a cultura política da Independência (1820-1822). Rio de Janeiro: Revan/ Faperj, 2003.

OLIVEIRA, Carlos Eduardo França de. Poder local e palavra impressa: a dinâmica política em torno dos conselhos provinciais e da imprensa periódica em São Paulo. Dissertação de mestrado, São Paulo, FFLCH-USP, 2010.

. Construtores do Império, defensores da província: São Paulo e Minas Gerais na formação do Estado nacional e dos poderes locais, 1823-1834. Tese de doutorado, FFLCH-USP, São Paulo, 2014.

OLIVEIRA, Cecília Helena de Salles. A astúcia liberal - Relações de mercado e projetos políticos no Rio de Janeiro (1820-1824). Bragança Paulista: Edusf/Ícone, 1999.

RIZZINI, Carlos. Hipólito da Costa e o Correio Braziliense. São Paulo: Companhia Editora Nacional, 1957.

SCHMIDT, Afonso. São Paulo de meus amores. São Paulo: Paz e Terra, 2003.

SENNET, Richard. O declínio do homem público: as tiranias da intimidade. São Paulo: Companhia das Letras, 1989.

SILVA, J. M. Pereira da. Segundo período do Reinado de dom Pedro I no Brazil. Rio de Janeiro: Garnier, 1871.

SILVA, Wlamir. Liberais e povo: a construção da hegemonia liberal-moderada na província de Minas Gerais. São Paulo: Hucitec, 2008.

SLEMIAN, Andréa. Vida política em tempo de crise: Rio de Janeiro, 1808-1824. São Paulo: Hucitec, 2004.

Sob o império das leis: constituição e unidade nacional na formação do Brasil (1822-1834). São Paulo: Hucitec, 2009.

SODRÉ, Nelson Werneck. História da imprensa no Brasil. Rio de Janeiro: Civilização Brasileira, 1966.

SOUSA, Octavio Tarquínio de. História dos fundadores do Império do Brasil, vol. VII. Evaristo da Veiga. Rio de Janeiro: José Olympio, 1957.

TILLY, Charles (ed.). The formation of the national states in western Europe. Princeton: Nova Jersey, USA: Princeton University Press, 1975.

VAINFAS, Ronaldo (dir.). Dicionário do Brasil imperial (1822-1889). Rio de Janeiro: Objetiva, 2002.

VIDAL, Geraldo. O marquês de Monte Alegre: alvorecer de um estadista. São Paulo: Ibrasa, 1999.

Recebido: 20/07/2014 - Aprovado: 11/11/2015 